\title{
EDITORIAL COMMENTS SPECIAL ISSUE ON ACCOUNTING EDUCATION
}

\author{
Dr Margaret Healy \\ University College Cork, Ireland \\ and \\ Dr Bríd Murphy \\ Dublin City University, Ireland
}

One of the hallmarks of a profession is the knowledge base to which its members stake ownership and the means through which control over future entrants is enacted and enabled. The epistemology and ontology of professional accountancy practice (Axford, 2005) serve to bind members to a common sense of identity, comprising the communities of practice representative of the accounting profession. Growing demands around employability and the toolkit of a set of transferrable skills place multiple demands on accounting educators. Coupled with growing pressure on resources, the increasingly managerialist nature of business school administration has led to concerns regarding the recruitment and training of future accountants and accounting academics (Flood, 2014; Fogarty, 2014; Guthrie, Burritt and Evans, 2012). This special issue of the Accounting, Finance and Governance Review is devoted to examining tensions appearing at the interface between expectations of students, employers, academics and professional bodies. The contributions in this special issue cover a range of topics of interest and relevance to the readership of the journal, evidencing the dual role of the lecturer as both educational interventionist and reflective practitioner/researcher. Each is briefly described below.

Given the ever-increasing pace of change within business and accounting, it is hugely important that today's accounting students learn how to learn. However, as argued by McWall and Wall in this special issue, student assessment within accounting tends to centre around formal examinations which align to professional exemptions. Related learning is largely teacher-led and student engagement focuses on activities that lead to success in these examinations. Providing a practitioner perspective, as educators in the specific context of audit education, McWall and Wall 
Healy and Murphy

consider whether student engagement and learning could be improved through a mixture of self-assessment and self-reflection activities. They describe and evaluate an intervention designed to promote student metacognition and provide students with a better understanding of examination technique, enhancing student ability to direct learning progress, building self-reliance and resilience.

McCutcheon, Healy and Doran posit that pedagogic change is required to ensure that accounting education is fit for purpose. Their paper focuses on the processes of cooperative and group learning, arguing that the extant literature has largely focused on the outcomes of group work grounded in specific group work interventions. The study empirically examines student approaches to and perceptions of group learning in the context of a four-year undergraduate programme of study, building on Tempone and Martin's (1999) framework. In so doing, they examine the relationships between students' approach to group work and the subsequent experiences of group work reported in relation to engagement and perceived value. The paper concludes that students and educators need to engage in a dialogue which addresses individual motivations and apprehensions; consequently, thereby constructing learning activities perceived as relevant by all stakeholders in accounting education.

A timely benchmark of doctoral education in the Irish context, positioning accounting student perceptions against Irish policy aspirations, is provided by Ward, Gorman and Brennan. Initially, they develop an analytical framework comprising measurable indicators of quality for doctoral education, classified into four dimensions: context, inputs, processes and outcomes. Data collected via semi-structured interviews are then combined with the content analysis of materials on higher education institutions' websites and prospectuses, to examine the extent to which accounting doctoral education across the island of Ireland complies with their analytical framework. Despite evidence suggesting a quality doctoral education system for accounting in Ireland, Ward et al. highlight particular concerns in relation to the low proportion of research-qualified accounting faculty and the lack of faculty at senior lecturer level or higher in Irish HEIs. Historic underinvestment in the development of a research culture in accounting departments must be addressed to enable the sector to reap the benefits of progress made in the provision of accounting doctoral education.

We would like to thank the contributors to this special issue. We are also grateful to the editors of the journal for suggesting this special issue and inviting us to be guest editors. As the number of papers in the educational domain being presented at the annual conference of the Irish Accounting and Finance Association has increased, the publication of this special issue provides a welcome marker of the importance of continued ongoing reflection on the integration of the research and teaching functions of the academic role. We would also like to extend sincere gratitude to and acknowledge the contributions of the reviewers of the papers submitted, who willingly contributed their time and expertise to this special issue. 


\section{REFERENCES}

Axford, B. (2005). Entering Professional Practice in the New Work Order: A Study of Undergraduate Students and Their Induction into Professional Work, The Australian Educational Researcher, Vol. 32, No. 2, pp. 87-104.

Flood, B. (2014). The Case of Change in Accounting Education, in R. Wilson (ed.), The Routledge Companion to Accounting Education, Oxford: Routledge, pp. 81-101.

Fogarty, T. (2014). The Bloom Is Off the Rose: Deprofessionalization in Public Accounting, in S. Mintz (ed.), Accounting for the Public Interest: Perspectives on Accountability, Professionalism and Role in Society, Dordrecht: Spinger, pp. 51-72.

Guthrie, J., Burritt, R. and Evans, E. (2012). Challenges for Accounting Pathways in Australia in 2012: An Introduction, in E. Evans, R. Burritt and J. Guthrie (eds), Emerging Pathways for the Next Generation of Accountants, Sydney, NSW: The Institute of Chartered Accountants in Australia/Centre for Accounting, Governance and Sustainability, University of South Australia, Academic Leadership series, pp. 9-15.

Tempone, I. and Martin, E. (1999). Accounting Students' Approaches to Group-Work, Accounting Education, Vol. 8, No. 3, pp.177-186. 